\title{
Decision-making Model for Determinant Factors of Business Digital Platform Adoption by SMEs
}

\author{
Debrina Puspita Andriani ${ }^{1}$, Wisnu Wijayanto Putro ${ }^{2}$, Sylvie Indah Kartika Sari ${ }^{3}$, Azizah Putri \\ Nur Aini ${ }^{4}$, Agustinus Alfian Anwar ${ }^{5}$ \\ \{debrina@ub.ac.id ${ }^{1}$ \} \\ Universitas Brawijaya, Indonesia ${ }^{1,2,3,4,5}$
}

\begin{abstract}
Small and medium enterprise (SMEs) is one of the industries that are currently growing rapidly. Its existence is not only a main pillar of the national economy, but also a pillar of family resilience. Most SMEs are family businesses that are driven, managed, and often employed their own families. The family presence had significant impact on the sustainability of SME businesses. However, empirical studies revealed contrary relationship between family ownership with the internationalization strategy of business, such as the strategy to adopt business digital platform or e-commerce for competing in the digital era. Therefore, this study aimed to assess and classify the determinant factors in business digital platform adoption that affect the SME businesses expansion. The decision making model is built in a decision tree using $\mathrm{C} 4.5$ algorithm. The results disclosed that organizational factor was the most significant factor in adopting a digital business platform. The organizational factors comprised enterprise resources, firm size, and management commitment. This study could support the business owners in making optimal and efficient decisions to minimize risk in order to create business and family sustainability and resilience.
\end{abstract}

Keywords: Decision Analysis, Digital Platform, Family Business, SME, Technology Adoption

\section{Introduction}

The labor absorption in small and medium enterprise (SMEs) contributes to the economy and national resilience. SMEs usually begin from a family business [1]. Ownership by the family becomes an advantage, especially in interaction and providing the capital, equipment, or other assets. Family capital is a unique combination of family values, social skills and ways of dealing with problems and challenges [2][3]. However, SMEs from a family business can be more risky than large-scale business and not a family business [4][5]. It caused by several obstacles, such as undercapitalization, poor timing and the wrong management decisions.

The commencement of industry 4.0 and social era 5.0 contributed to SME management activities [6]. These activities include production, administration, inventory, marketing, and so forth. From all of them, marketing were admitted as activities that were considered causing major issues to the SME existence [7][8]. The unique characteristics of SMEs, which are mostly family businesses, required a more in-depth analysis of the readiness in adopting the technology. The modification provoked by the digital era can be considered as supporting and obstacles factors to the sustainability of SME businesses [9]. On the other hand, business digital platform plays an important role in the growth of SMEs as it allows them to compete 
efficiently in both domestic and international markets [10][11].

The many factors that can influence SMEs in utilizing technology require further analysis. Several studies have been conducted from identifying factors and building in the proposal model. However, these studies have not shown the priority determinants and also the importance level of these factors [12]. This lead confusion in determining which one should be prioritized first. Coupled with limited resources and understanding, SMEs perceive that they were not ready to adopt a digital business platform [13].

Decision support system is a method used to support decision makers. One approach used in the decision support system is classification [14]. One method in classification is the C4.5 algorithm. C4.5 algorithm is the advancement of ID3 which are the decision tree method by running iterations with attributes [15]. This algorithm uses an induction approach where the data is divided based on the selected criteria to make a decision tree using a top-down approach. This algorithm is considered to have a smaller error rate when compared to other types of algorithms [16][17]. Based on the description, the objective of this study was to determinant factors that influence the decision to adopt and develop a digital business platform on SME business based on particular criteria. By utilizing technology through digital business platform, it was expected to enhance business sustainability of SMEs especially for facing the competition today.

\section{Research Method}

The study began with survey and literature studies to identify the problems. It was the subjectivity of determining determinants that influenced decision making in adopting and developing a digital business platform for SME businesses. The data required was the purpose and the factors that influenced the decision process. The decision purpose in this study was the adoption of a digital business platform at SME. The influencing factors were internal and external factors. Sub factors included in internal factors were organization, technology, individuals, and implementation. At the same time, external factors included the environment. A more detailed explanation of each factor was explained in the next chapter.

The decision model was illustrated in the decision tree diagram. The decision tree is popularly used as a method for prediction and classification [18][19]. Decision tree is a tree structure like a hierarchy or flowchart, where the top node is the root node. Decision tree techniques generate a flexible set of If-then rules. There are four more popularly used algorithms of decision trees i.e. ID3, CART, CHAID, C4.5. Prior study had explained that C4.5 technique had the highest accuracy compared to other algorithms [20][21]. Therefore, C4.5 algorithm used to build a decision model in this study.

C4.5 is a well-known algorithm used to generate the decision tree. It is an extension of ID3 algorithm used to overcome weaknesses. Decision trees generated by $\mathrm{C} 4.5$ algorithms can be used for classification, and for this reason, $\mathrm{C} 4.5$ also referred to as statistical groupings. C4.5 algorithms perform a number of changes to improve ID3 algorithm.

After collecting data with a random sample survey, training samples were processed. Training samples are samples used to perform a classification model in the decision tree [22], [23]. Through this process, entropy and gain were obtained. From the entropy results, the information gain was calculated. Information gain is a measure of the attribute effectiveness in classifying data. After got the information gain value, in gain ratio, normalization of the information gain was analyzed. In this step, the entropy was calculated from the probability 
distribution of the subset after partitioning. After that, decision tree node based on entropy and highest gain was build. This step was repeated until the decision tree included all criteria and decisions taken.

\section{Results and Discussion}

Internet-based trading offers great opportunities for companies to expand their marketing networks. Current data revealed positive growth in the Internet adoption rate by SMEs in a number of countries [24]. Although SMEs were increasingly using the Internet for various commercial and production-related purposes, they were still reluctant to optimize the use of business digital platform, especially electronic commerce. Lack of awareness of the platform enormous potential was one of the critical barriers to implementation, aside from other factors [25].

In addition to awareness factors, there were other factors identified that influenced the adoption of a business digital platform. Factor analysis in this study was in accordance with the results of prior studies that used various approaches in analyzing the determinant factors in technology adoption. These approaches include Theory Reasoned Action (TRA); the Theory of Planned Behavior (TPB); the Technology Acceptance Model (TAM); The Diffusion of Innovation Theory (DIT); and the Technological, Organizational and Environmental Framework (TOE). Each of these approaches has advantages and disadvantages that can be complementary [26].

\subsection{Identification of Factors and Sub-factors}

In this study, the main factors of digital platform adoption were divided into internal and external factors. Sub factors in the internal factor were organization, technology, individual, and implementation. While the external factors were the environment. From each of these sub factors represented several aspects. For example, the sub factors of organization represented aspects of enterprise resources, firm size, and management commitment. Figure 1 is a conceptual framework regarding the factors, sub factors, and aspects investigated in this study. 


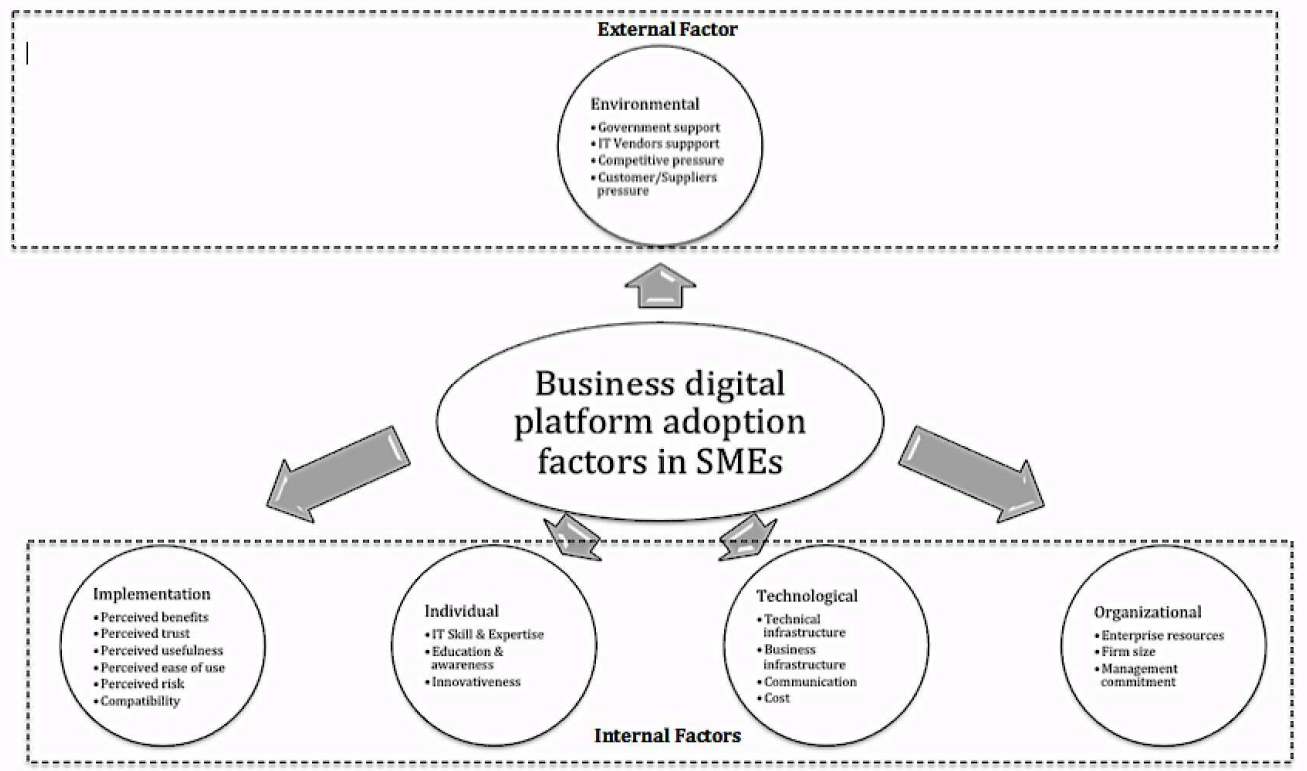

Fig. 1. Conceptual framework for business digital platform adoption in SMEs.

\subsubsection{Environmental Factor}

This factors included in the external factor. In this study, it was represented by government support, IT vendors support, competitive pressure, and customer/supplier pressure.

The government and IT vendor support is required in technology adoption. As is known, SMEs have limited resources, including IT skills resources. Thus the government support through policies or rules that can protect the elements involved in business transactions; regulation of internet safety for transactions; provision of infrastructure; and IT vendor support can increase this adoption rate [27].

In addition, environmental factors also refer to external influences such as competitive pressures from competitors and customers/suppliers. Competitive pressure has a positive influence on technology adoption [28]. More and more companies using the Internet for marketing and customer service will have a competitive impact and accelerate SMEs towards the adoption of business digital platform. Similarly, customers/suppliers have the power to pressure SMEs in adopting technology. For example, multinational companies often encourage their branches and suppliers to adopt business digital platform technology for connecting to their global production networks [29]. Therefore, the greater the pressure from trading partners perceived by SMEs, the more possible the adoption of a particular technology to maintain their competitive position [30].

\subsubsection{Organizational Factor}

Organizational factors included in internal factors. The organizational context refers to company characteristics that might influence the adoption of business digital platform 
technology. The context includes enterprise resources, firm size, and management commitment [31].

Firm size greatly influences firm decisions on digital platform adoption. This is related to the ability of a business to provide certain resources, whether financial, human or technological resources. The greater the firm size means the greater the ability to provide resources and the more possible the adoption of business digital platform technology [32].

Management support and enthusiasm is also very important for SMEs in the successful implementation of business digital platform. The manager or CEO innovation and IT knowledge had a positive effect on business digital platform adoption [33]. Individual characteristics such as the age, education, experience, and physiological nature of the CEO are an important part towards the adoption of Internet technology in SMEs.

\subsubsection{Technological Factor}

Technology readiness is one of the internal factors in influencing SMEs to adopt business digital platform. Technology readiness refers to the extent to which technology and business infrastructure can support the adoption of business digital platform [34]. Therefore, the greater of the technological readiness is the more possible the IT technology adoption, and vice versa [35].

Good infrastructure builds economic value for SMEs and also reduces operational costs [36]. Factors for the successful adoption of technology for SMEs in developing countries are also influenced by how the infrastructure interacts or communicates with its users. The communication factors include people, technical infrastructure, and client interface.

In this study, cost is also considered as a factor influencing SMEs in adopting business digital platform. The organization at some time felt that it was not relevant for their business and would cost too much to implement. Costs would also increase over time to maintain the system. Some recent studies explain that the cheaper the cost of a particular technology, the more possible it will be rapidly adopted and implemented in an organization [37].

\subsubsection{Individual Factor}

People are considered as the most important part towards the adoption of business digital platform in SMEs especially in developing countries. Individual factors consist of customers, staff, and business management, because they are people who are strongly influenced by business digital platform adoption.

Mostly in SMEs, strategic decisions are very dependent on the manager/owner. The adoption of business digital platform by SMEs is largely dependent on the acceptance of business digital platform technology by business owners [38]. This is because structurally SMEs tend to be centralized. The owner/manager has an important role in every business decision-making [39]. The adoption of business digital platform also has risks, especially if implemented in small businesses and even more so in developing countries. Therefore, owner's innovation, experience, and IT capabilities are identified as determining factors that influence SMEs in adopting business digital platform [40].

Education and awareness of those people are also considered, before and after business digital platform implementation. Many organizations postponed the adoption of business digital platform due to lack of competence and experience. Therefore, education and awareness along with IT skills and expertise are needed for any organization towards business digital platform adoption [41]. If managers/owners already know about business digital 
platform plus its benefits, organizations will be more likely to adopt business digital platform [30].

\subsubsection{Implementation Factor}

This factor is incorporated into internal factors because the impact is also a consideration for the successful adoption of a digital business platform. The digital platform that functions well is a professional digital platform to attract the right customers. Ease of use will be the key to successful adoption of a digital platform. This factor is usually represented as a friendly and interactive user interface. These quality attributes are general in software engineering and technology, so they can be widely used to ensure high levels of user acceptance [39].

In addition, customer trust factors towards security and privacy issues can affect the use and satisfaction of adopting a digital business platform [42]. This is one of the most severe barriers to business digital platform adoption between customers and sellers [43]. Trust is defined as the competency of a feature or system to act reliably and safely. Customer trust is important for the success of a business digital platform system, because it represents the capability, reliability, and integrity of the matter. Potential customers are very expensive to obtain when doubts arise about the truth of business processes. This certainly has an impact on profits and sustainability of the company.

When choosing to believe in the reliability of the digital business platform, risk factors are possible. Risks are described in terms of profit and loss [44]. Perceived risk is classified as a gain and loss scale that tends to reduce one's intention in adopting digital platform technology [45]. The benefits that business digital platform technology can provide to organizations are perceived benefits. Furthermore, improvement in work quality and organizational productivity are other empirical facts related to the usefulness of technology adoption. A greater managerial understanding of the relative advantages of business digital platform adoption increases the possibility of companies allocating some resources to adopt business digital platform technology.

The resource will determine digital platform compatibility with the SME. Compatibility refers to the extent to which business digital platform is compatible with technology and business infrastructure that already exists in the company [37]. An innovation will be easily accepted in an organization if it is adjusted to the values and needs of the organization. Compatibility between organizational policy and technological innovation will make innovation easier to implement.

\subsection{Data Analysis Using C4.5 Algorithm}

Data of this study were taken as many as 80 out of 100 SMEs which were random samples, because the rest were not willing to provide information. Based on Figure 2, Weka program, could result generate a percentage of $65 \%$ while 52 of the 80 data were classified correctly or properly classified examples. Thus $\mathrm{C} 4.5$ algorithms generated an acceptable level of accuracy.

Figure 2 also showed information about the confusion matrix. Confusion matrix describes about four classes and it forms $4 \times 4$ confusion matrix, the number of correctly classified instances is the sum of diagonals in the matrix $(33+11+4+4=52)$; remaining all are incorrectly classified instances.

According to $\mathrm{C} 4.5$ algorithm, it is clear from the confusion matrix of the true positive (TP) rate of this algorithm for the class 'a' yields higher $(0.825)$ than the other three classes. It 
means the algorithm is successfully classified and identified. Thus according to the results of TP and FP rate, it was concluded that the most important determinants of adoption of a digital business platform were organizational. The classification tree for this study is visualized in Figure 3.

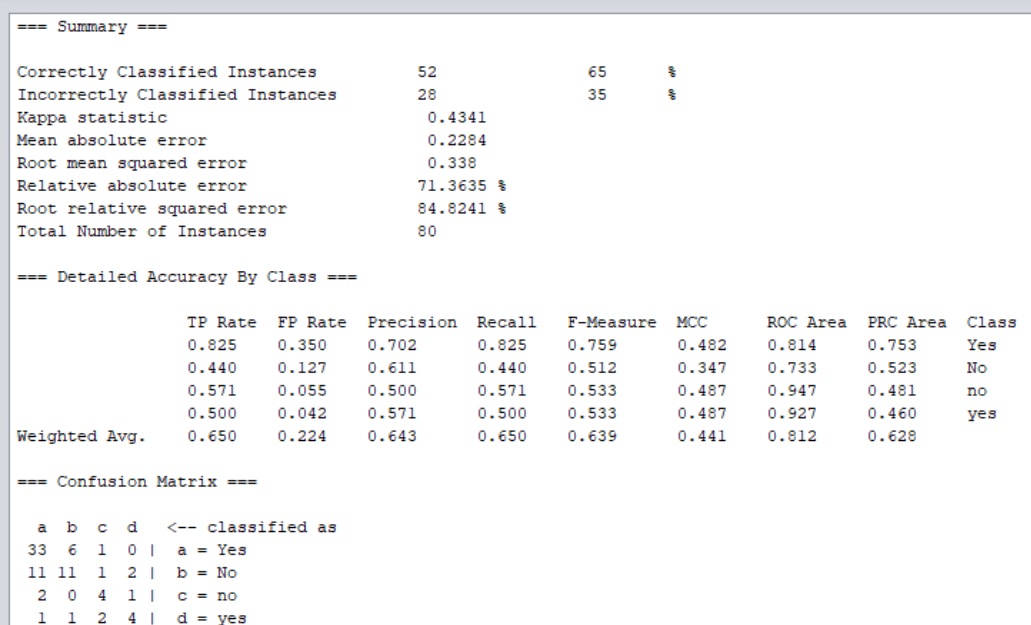

Fig. 2. Classifier output.

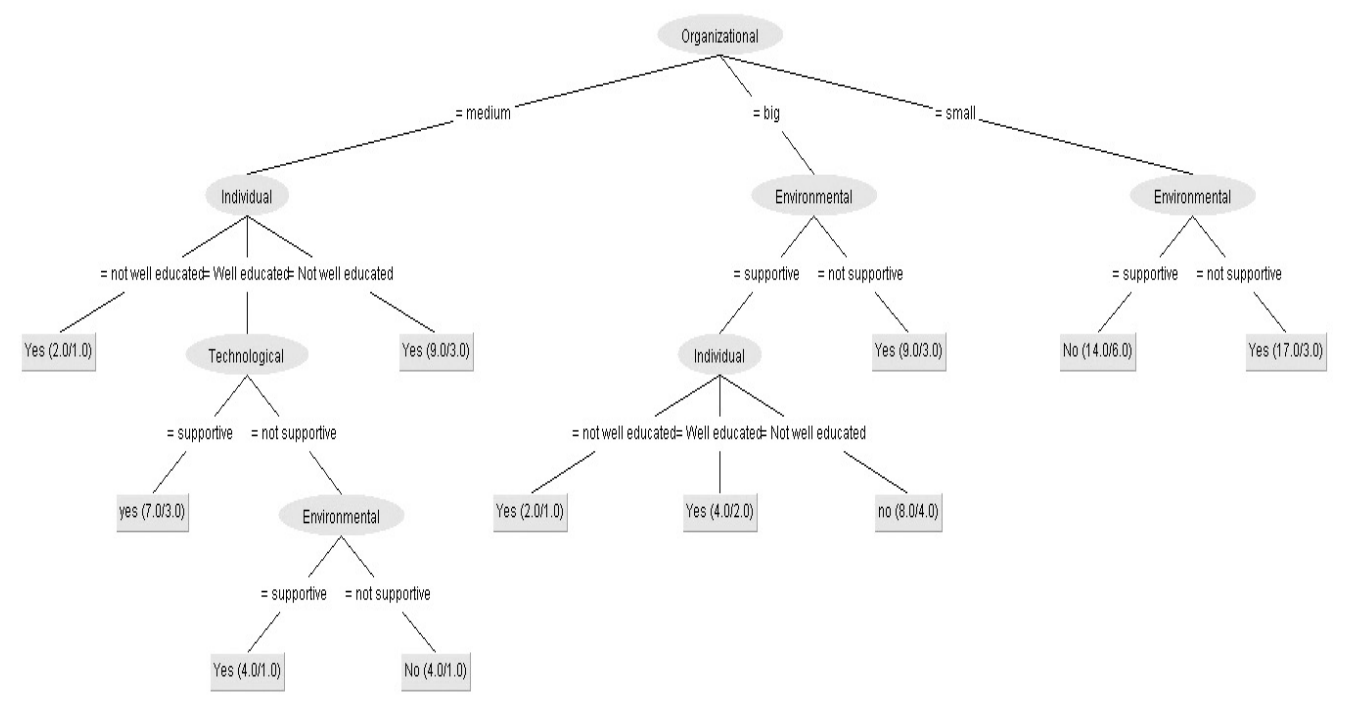

Fig. 3. Visualization of decision trees for business digital platforms adoption with $\mathrm{C} 4.5$ algorithm.

Figure 3 is the prioritization for the determinant factors of business digital platforms using decision trees. Organizational factors are taken as root nodes from individual, technological, and environmental nodes taken as branch nodes and so on. The knowledge represented by the decision tree can be extracted and represented in the form of IF-THEN 
rules as follows:

IF RULE

If Organizational $=$ medium, Individual $=$ well educated, technological $=$ supportive, Then YES adopted $\mathrm{E}$ - commerce

If organizational $=$ medium, individual $=$ not well educated, Then YES adopted $\mathrm{E}-$ commerce

If Organizational $=$ medium, individual $=$ well educated, technological $=$ not supportive, environmental $=$ supportive, Then YES Adopted E - commerce

If Organizational $=$ Big, Environmental $=$ not supportive, Then Not Adopted E - commerce

The main factor in the adoption of business digital platform found in this study was organizational factors, followed by implementation, individual, technological, and environmental. The organizational factors included firm size, enterprise resources and management commitment. This was because firm size is related to the company's business ability to provide specified resources, such as financial, human and technological resources. The larger the size of the business means greater its ability to provide a specific resource, so the more possible the adoption of business digital platform technology. Equipped with the support and enthusiasm of the management, the entire sub-factors on organizational factors to be very important for SMEs in determining the successful implementation of business digital platform.

Business owners mostly operate SMEs and the same person makes decisions at various levels. Although this makes SME management flexible and fast, and keeps it away from complex organizational structures, the success of SMEs remains inherent in the ability and skills of the owner. Owner awareness of the many potential benefits of business digital platform adoption is expected to increase. This is because the main obstacles prevent the adoption of electronic commerce are indifference and disinterest.

\section{Conclusion}

Small and medium scale businesses have (SMEs) have a crucial role to economic development, absorbing the large number of workers who contribute to GDP. It is well recognized that the majority of SMEs are family owned and are often managed by families. Business continuity depends on how the manager / owner manages the business, including technology adoption.

Digital business platform is a technology adoption that is profitable for SMEs. However, many SMEs in developing countries are still reluctant to adopt it. The identification results indicated several factors that influenced the adoption. These factors were internal and external factors. Internal factors included organization, technology, individuals, and implementation. While external factors included the environment.

The linkages between these factors are classified and formed in the decision making model. The model is presented in a decision tree using the C4.5 algorithm approach. The results show that the model generates $65 \%$ of the data correctly classified. 
In addition, the results also showed that a very influential factor in the adoption of a digital business platform was organizational factors, followed by implementation, individual, technological, and environmental. In organizational factors known sub factors involved include enterprise resources, firm size, and management commitment. Therefore, the role of manager/owner is required in supporting the adoption of a digital business platform at SME.

\subsection{Acknowledgement}

The authors express gratitude to Institute for Research and Community Service (IRCS) dan Statistical \& Quality Engineering Laboratory, Brawijaya University, Indonesia for extraordinary support.

\section{References}

[1] T. F. González-Cruz and S. Cruz-Ros, "When does family involvement produce superior performance in SME family business?," J. Bus. Res., vol. 69, no. 4, pp. 1452-1457, 2016.

[2] A. De Massis, J. Kotlar, G. Campopiano, and L. Cassia, "The impact of family involvement on SMEs' performance: Theory and evidence,” J. Small Bus. Manag., vol. 53, no. 4, pp. 924-948, 2015.

[3] D. Miller, A. Minichilli, and G. Corbetta, "Is family leadership always beneficial?," Strateg. Manag. J., vol. 34, no. 5, pp. 553-571, 2013.

[4] S. A. Zahra, "Entrepreneurial risk taking in family firms," Fam. Bus. Rev., vol. 18, no. 1, pp. 23-40, 2005.

[5] Z. Fernández and M. J. Nieto, "Internationalization strategy of small and medium-sized family businesses: Some influential factors," Fam. Bus. Rev., vol. 18, no. 1, pp. 77-89, 2005.

[6] D. P. Andriani, A. P. Aini, A. N., and R. Adnandy, Risks analysis on digital platforms adoption to elevate SME businesses in developing country. IOP Conf. Series: Materials Science and Engineering. 2019.

[7] E. Triandini, A. Djunaidy, and D. Siahaan, "Factors Influencing E-Commerce Adoption by SMES Indonesia: A Conceptual Model," Lontar Komput. J. Ilm. Teknol. Inf., 2013.

[8] M. Z. Muhammad, A. K. Char, M. R. bin Yasoa, and Z. Hassan, "Small and medium enterprises (SMEs) competing in the global business environment: A case of Malaysia," Int. Bus. Res., vol. 3 , no. 1, p. 66, 2010.

[9] F. Nejadirani, M. Behravesh, and R. Rasouli, "Developing countries and electronic commerce the case of SMEs," World Appl. Sci. J., vol. 15, no. 5, pp. 756-764, 2011.

[10] D. Consoli, "Literature analysis on determinant factors and the impact of ICT in SMEs," Procedia-social Behav. Sci., vol. 62, pp. 93-97, 2012.

[11] E. Segaro, "Internationalization of family SMEs: the impact of ownership, governance, and top management team," J. Manag. Gov., vol. 16, no. 1, pp. 147-169, 2012.

[12] F. Ajmal and N. M. Yasin, "Model for electronic commerce adoption for small and medium sized enterprises,” Int. J. Innov. Manag. Technol., vol. 3, no. 2, pp. 90-94, 2012.

[13] D. P. Price, M. Stoica, and R. J. Boncella, "The relationship between innovation, knowledge, and performance in family and non-family firms: an analysis of SMEs," J. Innov. Entrep., vol. 2, no. 1, p. 14, 2013.

[14] A. K. Sharma and S. Sahni, "A comparative study of classification algorithms for spam email data analysis," Int. J. Comput. Sci. Eng., vol. 3, no. 5, pp. 1890-1895, 2011.

[15] T. M. Lakshmi, A. Martin, R. M. Begum, and V. P. Venkatesan, "An analysis on performance of decision tree algorithms using student's qualitative data," Int. J. Mod. Educ. Comput. Sci., vol. 5 , no. 5, p. 18, 2013.

[16] P. A. and Et.al, "Comparative Analysis of Decision Tree Classification Algorithms," Int. J. Curr. Eng. Technol., vol. 3, no. 2, pp. 334-337, 2013. 
[17] V. K. Nijhawan, M. Madan, and M. Dave, "The Analytical Comparison of ID3 and C4. 5 using WEKA,” Int. J. Comput. Appl., vol. 167, no. 11, pp. 1-4, 2017.

[18] B. Nithyassik and Et.al, "Classification Techniques in Education Domain," Int. J. Comput. Sci. Eng., vol. 2, no. 5, pp. 1647-1684, 2010.

[19] B. K. Bhardwaj and S. Pal, "Data Mining: A prediction for performance improvement using classification (IJCSIS) International Journal of Computer Science and Information Security 9," 2011.

[20] B. Hssina, A. Merbouha, H. Ezzikouri, and M. Erritali, "A comparative study of decision tree ID3 and C4. 5," Int. J. Adv. Comput. Sci. Appl., vol. 4, no. 2, pp. 13-19, 2014.

[21] K. Adhatrao, A. Gaykar, A. Dhawan, R. Jha, and V. Honrao, "Predicting students' performance using ID3 and C4. 5 classification algorithms," arXiv Prepr. arXiv1310.2071, 2013.

[22] M. Kantardzic, Data Mining: Concepts, Models, Methods, and Algorithms. Wiley-IEEE Press, 2011.

[23] J. Han, J. Pei, and M. Kamber, Data mining: concepts and techniques. Elsevier, 2011.

[24] OECD, A New Economy? - The Role of Innovation and Information Technology in Recent OECD Economic Growth. DSTI/IND/STP/ICCP(2000)1/REV1. .

[25] M. Savrul, A. Incekara, and S. Sener, "The potential of e-commerce for SMEs in a globalizing business environment," Procedia-Social Behav. Sci., vol. 150, pp. 35-45, 2014.

[26] R. Rahayu and J. Day, "Determinant factors of e-commerce adoption by SMEs in developing country: evidence from Indonesia," Procedia-Social Behav. Sci., vol. 195, pp. 142-150, 2015.

[27] H. El-Gohary, "Factors affecting E-Marketing adoption and implementation in tourism firms: An empirical investigation of Egyptian small tourism organisations," Tour. Manag., vol. 33, no. 5, pp. 1256-1269, 2012.

[28] N. Al-Qirim, "The adoption of eCommerce communications and applications technologies in small businesses in New Zealand," Electron. Commer. Res. Appl., vol. 6, no. 4, pp. 462-473, 2007.

[29] C. L. Iacovou, I. Benbasat, and A. S. Dexter, "Electronic data interchange and small organizations: Adoption and impact of technology," MIS Q., pp. 465-485, 1995.

[30] X. Duan, H. Deng, and B. Corbitt, "Evaluating the critical determinants for adopting e-market in Australian small-and-medium sized enterprises," Manag. Res. Rev., 2012.

[31] M. A. Rashid, "E-commerce technology adoption framework by New Zealand small to medium size enterprises," 2001.

[32] L. Pham, L. N. Pham, and D. T. T. Nguyen, "Determinants of e-commerce adoption in Vietnamese small and medium sized enterprises," Int. J. Entrep., vol. 15, p. 45, 2011.

[33] B. Ramdani, D. Chevers, and D. A. Williams, "SMEs' adoption of enterprise applications: A technology-organisation-environment model," J. Small Bus. Enterp. Dev., vol. 20, no. 4, pp. 735-753, 2013.

[34] T. H. Nguyen and T. S. Waring, "The adoption of customer relationship management (CRM) technology in SMEs: An empirical study," J. Small Bus. Enterp. Dev., vol. 20, no. 4, pp. 824848, 2013.

[35] I. Sila, "Factors affecting the adoption of B2B e-commerce technologies," Electron. Commer. Res., vol. 13, no. 2, pp. 199-236, 2013.

[36] M. Ghobakhloo and S. H. Tang, "The role of owner/manager in adoption of electronic commerce in small businesses: The case of developing countries," J. small Bus. Enterp. Dev., vol. 20, no. 4, pp. 754-787, 2013.

[37] M. Ghobakhloo, D. Arias-Aranda, and J. Benitez-Amado, "Adoption of e-commerce applications in SMEs," Ind. Manag. Data Syst., 2011.

[38] A. Hamelin, "Influence of family ownership on small business growth. Evidence from French SMEs," Small Bus. Econ., vol. 41, no. 3, pp. 563-579, 2013.

[39] S. S. Al-Gahtani, "Modeling the electronic transactions acceptance using an extended technology acceptance model," Appl. Comput. informatics, vol. 9, no. 1, pp. 47-77, 2011.

[40] S. K. Katsikas, J. Lopez, and G. Pernul, "Trust, privacy and security in e-business: Requirements and solutions," in Panhellenic Conference on Informatics, 2005, pp. 548-558. 
[41] N. Chiliya, C. K. Chikandiwa, and F. Bola Afolabi PhD, "Factors Affecting Small Micro Medium Enterprises'(SMMEs) Adoption of E-Commerce in the Eastern Cape Province of South Africa," Int. J. Bus. Manag., vol. 6, no. 10, p. 28, 2011.

[42] H.-H. Lee and E. Chang, "Consumer attitudes toward online mass customization: An application of extended technology acceptance model," J. Comput. Commun., vol. 16, no. 2, pp. 171-200, 2011.

[43] S. Shah Alam, M. Y. Ali, and M. F. Mohd. Jani, "An empirical study of factors affecting electronic commerce adoption among SMEs in Malaysia," J. Bus. Econ. Manag., vol. 12, no. 2, pp. 375-399, 2011.

[44] D. P. Andriani, V. D. Novianti, R. Adnandy, and Q. A'yunin, "Quantitative risk modelling of occupational safety in green-port," in IOP Conference Series: Materials Science and Engineering, 2019, vol. 546, no. 5, p. 52007.

[45] T. Oliveira and M. F. Martins, "Understanding e-business adoption across industries in European countries,” Ind. Manag. Data Syst., vol. 110, no. 9, pp. 1337-1354, 2010. 